\title{
Olhares docentes: caracterização do Ensino de Ciências em uma rede municipal de ensino perante a BNCC
}

\author{
Vanessa de Cassia Pistóia Mariani ${ }^{\star}$, Lenira Maria Nunes Sepel ${ }^{\star *}$
}

\section{Resumo}

Este artigo tem como objetivo analisar entendimentos de docentes de $4^{\circ}$ e $5^{\circ}$ anos do Ensino Fundamental em relação à organização curricular da Área de Ciências da Natureza na BNCC e aos Planos de Estudos das escolas da rede municipal em que atuam, considerando as Unidades Temáticas, os Objetos do Conhecimento e as Habilidades. Trata-se de uma pesquisa qualitativa na forma de estudo de caso, envolvendo nove docentes atuantes no $4^{\circ}$ e $5^{\circ}$ ano de uma rede municipal do interior do estado do RS. Na produção de dados são considerados os princípios da análise de conteúdo e são tomados Planos de Estudos de sete escolas, um formulário avaliativo composto por onze itens para o $4^{\circ}$ ano e treze para o $5^{\circ}$ ano e um questionário que composto por três questões abertas e duas fechadas, envolvendo informações sobre os Planos de Estudos e os Objetos de Conhecimentos da BNCC (BRASIL, 2017), ambos preenchidos pelos participantes da pesquisa no decorrer de um programa de formação continuada. Os aportes teóricos que fundamentam as análises são, além da própria BNCC (BRASIL, 2017), Sacristán (1995,1998, 2013), Vasconcellos (2014) e Menegolla e Sant'Anna (2014), em relação ao planejamento docente, e Carvalho (2011, 2013), Franco e Munford (2018) e Compiani (2018), no que tange ao ensino de Ciências da Natureza. Como resultados observam-se divergências entre os Planos Estudos das escolas investigadas frente os Objetos de Conhecimento e Habilidades apresentadas pela BNCC, porém a maioria dos docentes avalia que os preceitos contidos na BNCC podem ser aplicáveis em suas aulas. Quanto à forma como estão dispostos os Objetos do Conhecimento, os docentes destacam a organização das Unidades Temáticas, a ênfase atribuída as atividades práticas e o favorecimento em relação a aprendizagem e compreensão dos saberes.

Palavras-chave: Políticas Educacionais; Currículo; Ensino de Ciências.

* Docente do IFFAR. Doutoranda do PPG-Educação em Ciências- Química da Vida e Saúde- UFSM, Brasil. E-mail: vcpmariani@gmail.com

* Docente do PPG-Educação em Ciências- Química da Vida e Saúde- UFSM, Brasil. E-mail: lenirasepel@gmail.com

Recebido em: 30/09/2019 - Aceito em: 05/12/2019.

https://doi.org/10.5335/rbecm.v3i1.10022

http://creativecommons.org/licenses/by-nc-nd/4.0 


\section{Introdução}

Vivemos em tempos de mudanças na organização do sistema educacional brasileiro, impulsionadas ao longo dos últimos anos, principalmente, pela Lei de Diretrizes e Bases da Educação Nacional 9394/96 e pelas leis ํo 12.796 , de 2013 e $\mathrm{n}^{\mathrm{o}}$ 13.415, de 2017, que configuram um novo panorama educativo. Como fruto destas transformações temos a elaboração e implementação da Base Nacional Comum Curricular (BNCC) homologada por meio da Portaria $\mathrm{n}^{\circ}$ 1.570 da BNCC publicada em 21 de dezembro de 2017, no Diário Oficial da União.

A eminência de adaptação dos currículos escolares frente aos aspectos propostos pela BNCC mobiliza gestores e educadores de todo o país com intuito de iniciar a transposição didática do que está posto neste documento para realidades específicas. Muitos aspectos organizacionais das escolas necessitam ser revistos, dentre eles estão os Projetos Políticos Pedagógicos e os Planos de Estudos. O CNE (Conselho Nacional de Educação) através da Resolução CNE/CP № 2, de 22 de dezembro de 2017, busca instituir e orientar a implantação da BNCC, a ser respeitada obrigatoriamente ao longo das etapas e respectivas modalidades no âmbito da Educação Básica. Conforme enfatizado no Artigo $5^{\circ}$, parágrafo $1^{\circ}$ a BNCC deve fundamentar a concepção, formulação, implementação, avaliação e revisão dos currículos, e consequentemente das propostas pedagógicas das instituições escolares, contribuindo, desse modo, para a articulação e coordenação de políticas e ações educacionais desenvolvidas em todas as redes de ensino.

Frente a essa realidade, buscamos analisar entendimentos de docentes de $4^{\circ}$ e $5^{o}$ anos do ensino fundamental em relação à organização curricular da Área de Ciências da Natureza na BNCC e aos Planos de Estudos das escolas da rede municipal em que atuam, considerando as Unidades Temáticas, os Objetos do Conhecimento e as Habilidades.

\section{A BNCC e a Área de Ciências da Natureza}

O processo de elaboração da BNCC iniciou em 2015, a partir da nomeação da Comissão de Especialistas para a Elaboração de Proposta da Base Nacional Comum Curricular. Conforme a Portaria n⿳ำ 592, de 17 de junho de 2015, cento e dezesseis docentes de diferentes áreas e níveis de formação deveriam delinear o 
documento preliminar. A primeira versão foi disponibilizada em 15 de setembro de 2015, e em dezembro do mesmo ano, as escolas foram mobilizadas para analisarem tal documento. No ano de 2016 foi divulgada, em 03 de maio, a segunda versão da BNCC, e de 23 de junho a 10 de agosto foram realizados 27 seminários estaduais de debate, organizados pelo Conselho Nacional de Secretários de Educação (Consed) e a União Nacional dos Dirigentes Municipais de Educação (Undime). A partir do mês de agosto de 2017, começou a ser redigida a terceira versão, em um processo colaborativo, com base nos apontamentos realizados nas discussões anteriores. No ano de 2017, durante o mês de abril, o MEC entregou a versão final da BNCC correspondente às etapas da Educação Infantil e Ensino Fundamental ao CNE, a qual foi homologada dezembro de 2017.

A BNCC em sua versão final, constitui-se em um documento extenso e complexo, composto por aspectos teóricos, legais, metodológicos e conceituais que buscam reorganizar os currículos escolares no Brasil. Os textos iniciais deste documento, apresentam as bases legais, os fundamentos pedagógicos, o pacto Inter federativo para a implementação entre União, Estados, Distrito Federal e Municípios, e estrutura da BNCC para a Educação Infantil e Ensino Fundamental, proporcionando uma visão geral preparando para os desdobramentos das áreas de conhecimento que vem a seguir.

No Ensino Fundamental, a BNCC organiza os conhecimentos em cinco áreas. Duas que abarcam mais de um componente curricular, como é o caso de Linguagens (que é composta por Língua Portuguesa, Arte, Educação Física e Língua Inglesa) e Ciências Humanas (que reúne Geografia e História), e outras três que consideram apenas um componente curricular, ou seja, Matemática, Ensino Religioso e Ciências da Natureza, sendo que essa última se refere exclusivamente ao componente Ciências. Cada área do conhecimento contém uma apresentação, competências específicas cujo desenvolvimento deve ser promovido ao longo dos nove anos, apresentação dos componentes curriculares que compõe a área e competências específicas de cada componente, considerando uma organização em anos iniciais e anos finais que explicitam Unidades Temáticas, Objetos do Conhecimento e Habilidades. 
As unidades temáticas definem um arranjo dos objetos do conhecimento ao longo do Ensino Fundamental adequando às especificidades dos diferentes componentes curriculares. Cada Unidade Temática contempla uma gama maior ou menor de objetos de conhecimento, assim como cada objeto do conhecimento de relaciona a um número variável de habilidades (BRASIL, 2017, p. 29, grifo do autor).

As Habilidades são desdobramentos dos Objetos do Conhecimento expressando aprendizagens essenciais e descritas de forma a englobar o processo cognitivo envolvido, o Objeto do Conhecimento a ser mobilizado e o contexto ou dimensão da aprendizagem.

A Resolução do CNE/CP № 2, de 22 de dezembro de 2017, define as competências para cada área do conhecimento que devem ser agregadas aos currículos e as práticas docentes, dando ênfase nas Ciências da Natureza para a: compreensão das Ciências da Natureza como empreendimento humano e o conhecimento científico como provisório, cultural e histórico; o entendimento e domínio conceitos fundamentais, processos, práticas e procedimentos da investigação científica; reconhecimento de características, fenômenos e processos relativos ao mundo natural, social e tecnológico (incluindo o digital); avaliação das aplicações e implicações políticas, socioambientais e culturais da ciência e de suas tecnologias; construção de argumentação baseado em dados científicos aprimorando a consciência ambiental, desenvolvimento de postura individual e coletiva de respeito, autonomia, responsabilidade, flexibilidade, resiliência e determinação; entre outros.

Frente a estas competências percebemos a importância atribuída área de Ciências da Natureza como mobilizadora de saberes e práticas humanas capazes de compreender e melhorar a intervenção humana no planeta. Para tanto reúne saberes que buscam desenvolver compreensões sobre o mundo e suas transformações, além de um compromisso com o letramento científico, envolvendo o entendimento e interpretação do mundo natural, social, tecnológico com vistas a transformação através do uso de teorias e processos científicos (BRASIL, 2017).

Carvalho (2011) enfatiza que é importante introduzir os alunos no universo das Ciências desde cedo, proporcionando oportunidades para a observação dos problemas do mundo, elaboração de estratégias e definição de plano de ação, dentro de uma perspectiva de Ciências por investigação, desenvolvendo assim reais habilidades que permitam uma atuação consciente e racional no mundo. Já Rosa et al. (2007) destacam que o processo de alfabetização científica e tecnológica é fundamental 
para ocorra o desenvolvimento de indivíduos tenham uma participação crítica e consciente na sociedade.

A versão final da BNCC referente à etapa do Ensino Fundamental apresenta eixos formativos dentro de uma abordagem investigativa de Ensino de Ciências, organizados a partir de: a) Definição de problemas; b) Levantamento, análise e representação, avaliação da informação ao problema colocado; c) Comunicação, organização e/ou extrapolação de conclusões; d) Intervenção, desenvolvimento de ações de intervenção para melhorar a qualidade de vida individual, coletiva e socioambiental (COMPIANI, 2018) Além disso, o mesmo autor evidencia que tal documento atribui grande ênfase no eixo conceitual e das práticas investigativas enfraquecendo o eixo contextual e das linguagens.

Compiani (2018) também analisa que na versão anterior, ou seja, a proposta em 2016, os conhecimentos da área de Ciências da Natureza eram subdivididos em cinco unidades de conhecimento:1-Materiais, Propriedades e transformações; 2 - Ambiente, Recursos e Responsabilidades; 3 - Terra: Constituição e Movimento; 4 - Vida: Constituição e Evolução; 5 - Sentidos, Percepção e Interações. No entanto, a versão aprovada, contém apenas três Unidades Temáticas: Matéria e Energia, Vida e Evolução e Terra e Universo que visam desenvolver Objetos do Conhecimento e Habilidades de forma progressiva e continua ao longo de todo o Ensino Fundamental, garantido um elo entre todos os anos escolares. Cada unidade temática abarca um nicho específico de saberes que se integram as demais Unidades Temáticas e também as demais Áreas do Conhecimento que compõe o ano escolar.

A Unidade Temática Matéria e Energia: "Contempla o estudo dos materiais e suas transformações, fontes e tipos de energia utilizados na vida em geral, na perspectiva de construir conhecimento sobre a natureza da matéria e os diferentes usos da energia" (BRASIL, 2017 p. 323). Essa unidade concentra assuntos referentes a utilização, ocorrência e processamento de recursos naturais e energéticos, mais vinculados com o cotidiano dos alunos dos anos iniciais, os elementos mais concretos e os ambientes que o cercam explorando noções primárias, usos, propriedades, interações e reutilizações, com foco, conforme Compiani (2018), nas áreas de química e física.

A Unidade Temática Vida e Evolução aborda questões relacionadas aos seres vivos (incluindo o ser humano) explorando suas características, desenvolvimento, necessidades, relações com ecossistemas e interações, centrando-se na área de biologia. Nos anos iniciais as análises podem acorrer a partir de animais de seu 
convívio e com seu próprio corpo explorando aspectos sobre desenvolvimento saudável, nutricional e elos como o ambiente natural.

A Unidade Temática Terra e Universo explora as características sobre o Sol, a Lua e a Terra, assim como outros corpos celestes, a partir de suas dimensões, localizações, composições e movimentos e forças que atuam entre eles, como os alunos potencializam ações de observação e descrição de fenômenos, assim como relações com o conhecimento histórico e científico já construído, centrando-se em áreas de geociências e astronomia. E nesse sentido, Compiani (2018), destaca que a versão final da BNCC contém uma ampliação de conhecimentos relacionados à astronomia, quando comparado com as duas versões anteriores.

Em síntese, a figura 1, contém as três unidades temáticas da área de Ciências da Natureza e os Objetos do Conhecimento referentes aos anos iniciais do Ensino Fundamental, conforme Brasil (2017).

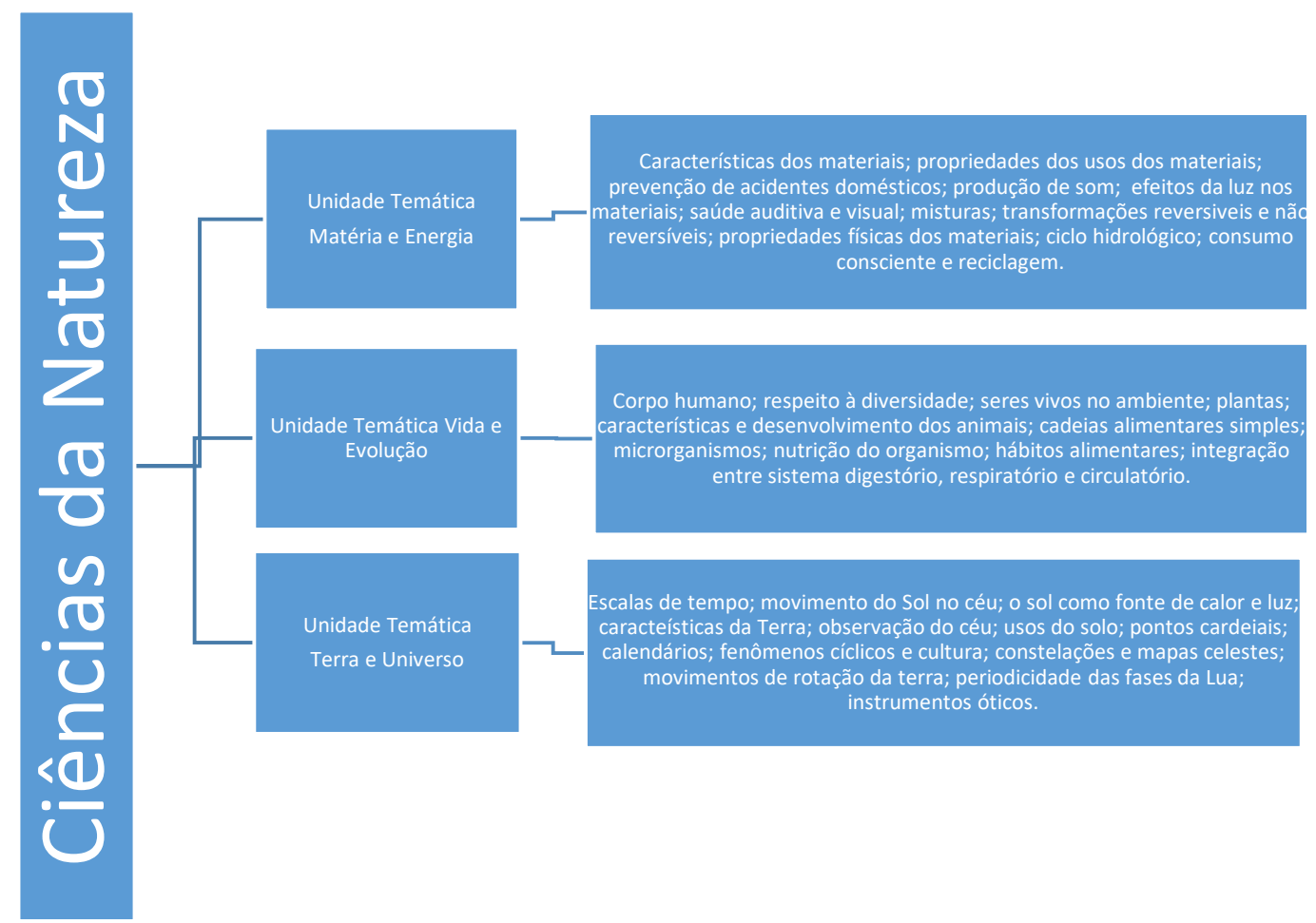

Fonte: Compilação de dados da BNCC- Área de Ciências a Natureza (BRASIL, 2017). 
Nessa perspectiva, ainda é cabível ressaltar críticas dirigidas à Área de Ciências da Natureza na BNCC como, por exemplo, a forma de organização, seleção de conteúdos e habilidades e condução do material apresentado, conforme Franco e Munford (2018) e Compiani (2018). Além disso, observam-se ressalvas quanto à abordagem discursiva que silencia diferentes interlocutores e prejudica a compreensão das perspectivas educativas do Ensino de Ciências presentes no documento, segundo Flôr e Trópia (2018).

\section{A organização curricular a partir da BNCC}

A BNCC não se caracteriza como um currículo a ser apenas implementado nas escolas, e sim um documento oficial de caráter normativo que organiza as áreas do conhecimento, competências, objetivos, objetos do conhecimento e habilidades que necessitam ser incorporadas ao verdadeiro currículo de cada instituição escolar, em seu sentido amplo de realidade, contexto e relações que se formam a partir de caraterísticas específicas de cada lugar. Diante do exposto, corroboramos com a definição de currículo apresentada por Sacristán (2013) o qual destaca que currículo é um conceito complexo que abarca muitas dimensões envolvendo práticas políticas, econômicas, sociais, didáticas, de supervisão do sistema escolar; desenvolvendo-se dentro e fora da instituição escolar.

Por currículo entendemos a complexa trama de experiências que o aluno obtem, incluídos os efeitos do currículo oculto, o plano deve contemplar não apenas a atividade de ensino dos professores, mas também todas as condições do ambiente de aprendizagem graças às quais se produzem esses efeitos: relações sociais na aula e na escola, uso de textos escolares, efeitos derivados das práticas de avaliação, etc (SACRISTÁN, 1995, p. 230).

Sacristán (1998), destaca que para fins de estudo podemos organizar o currículo em dimensões que se entrelaçam e estão em constante negociação, retomada e reorganização que são: currículo prescrito que se expressa através dos documentos curriculares, diretrizes que definem, entre outras coisas os conteúdos mínimos a serem ensinados e a cultura comum com um caráter de homogeneidade; currículo apresentado aos professores: a tradução para os docentes do conteúdo do currículo explicito de forma mais clara, geralmente realizada através dos livros didáticos; currículo moldado pelos professores: adaptação de acordo com a realidade 
docente, utilizando o prescrito e o apresentado, é o momento em que o professor é ativo e decisivo no processo de construção de significados do currículo; currículo em ação: é onde o professor interage e coloca em prática suas concepções teóricas e práticas; currículo realizado: que são os rendimentos gerados pela prática, sejam cognitivos, afetivos, sociais, morais...; currículo avaliado: se expressa nas avaliações do processo de ensino-aprendizagem, que ocorrem no interior da escola e nas avaliações externas.

Segundo Sacristán (1998), há um conjunto de elementos que influenciam e são influenciados pelas práticas dos professores, desde a definição de políticas educacionais, passando pelas diretrizes da instituição em que atua, pelas relações entre pares e outros envolvidos no processo educacional, até a sua experiência e visão em relação tanto ao curso como à disciplina específica com a qual trabalha. Frente a esta nova organização e gama de saberes apresentados pela BNCC cabe a reorganização dos currículos escolares em todas as áreas do conhecimento. As unidades escolares de todo o país necessitam reformular seus Projetos Políticos Pedagógicos (PPP), Regimentos e Planos de Estudos a fim de alinhar seus currículos com este documento, acrescentando especificidades de sua realidade e de suas regiões. Assim, parte-se para uma série de estudos, análises, discussões que devem mobilizar as escolas, considerando os docentes como parceiros importantes neste processo.

Os Planos de Estudos ou Planos Curriculares fazem parte dos regimentos escolares que definem a organização legal da escola, são alicerces na prática dos docentes caracterizando-se por conter a relação de conteúdos mínimos a serem desenvolvidos durante o ano escolar determinado. Tais planos, assim como o PPP, são organizados pelas próprias instituições e seguem as orientações das diretrizes curriculares vigentes e suas mantenedoras, podendo ter diferentes formatos, desde uma lista de conteúdos a serem abordados até habilidades, e saberes a serem desenvolvidos, de acordo com linha teórica e metodológica que foi utilizada como base para sua elaboração. Nessa perspectiva consideramos que o Plano Curricular:

É o processo de tomada de decisões sobre a dinâmica da ação escolar. É previsão sistemática e ordenada de toda a vida escolar do aluno. Portanto, essa modalidade de planejar constitui um instrumento que orienta a ação educativa na escola, pois a preocupação é com a proposta geral das experiências de aprendizagem que a escola deve oferecer ao estudante, através dos diversos componentes curriculares (VASCONCELLOS, 2014, p. 56). 
Vasconcellos (2014) ainda enfatiza que, na maioria das vezes, as propostas curriculares são feitas pelos sistemas estaduais ou municipais, dando origem aos chamados "Guias Curriculares" que em princípio, deveriam ser apenas uma orientação para as escolas, mas que na prática, acabam sendo entendidos e cobrados como programa oficial a ser executado. Em contraponto, é indispensável que os docentes sejam mobilizados a participar e recriar Planos de Estudos, assumindo protagonismo, pois são os reais conhecedores da realidade escolar.

Menegolla e Sant`Anna (2014) enfatizam que todo o processo educacional requer planejamento em termos nacionais, estaduais, regionais, comunitários, inclusive em nível de escolar no que tange ao ensino e às diferentes disciplinas e conteúdos a serem desenvolvidos. Destacam ainda que

À escola cabe, partindo da sua realidade e de suas necessidades e possibilidades, estruturar e organizar os seus planos. Estes planos são, propriamente, os planos curriculares que servirão de base para todo o processo educativo da escola (MENEGOLLA e SANT`ANNA, 2014, p. 35).

Através de estudos recentes Mariani e Sepel (2019b) constatam docentes que participaram do processo de consulta pública da BNCC, expressam informações condizentes com materiais de divulgação utilizados por órgãos oficiais ou apoiadores da elaboração desta política pública. Porém as autoras apontam a necessidade de ampliação desses entendimentos, no que se refere principalmente as áreas específicas, como as Ciências da Natureza, a fim de obterem um maior aprofundamento teórico e metodológico que sustentem a implementação nos currículos escolares.

\section{Percursos da pesquisa}

A pesquisa desenvolve-se a partir de uma abordagem qualitativa, que segundo Sampieri et al (2013) tem como objetivo compreender e aprofundar os fenômenos estudados conforme perspectivas dos participantes em um ambiente natural e em relação a um contexto. Para Yin (2016, p.25) enfatiza que a condição inicial deriva do desejo da pesquisa qualitativa de capturar o significado dos eventos da vida real, da perspectiva dos participantes de um estudo. Quanto aos procedimentos caracteriza-se por um estudo de caso, pois possibilita o conhecimento de fenômenos individuais, organizacionais, sociais, políticos e de grupo, preservando as características holísticas e significativas dos acontecimentos da vida real (YIN, 2005, p.20). 
Nessa perspectiva, o campo deste estudo de caso é o Programa de Formação Continuada: Ensino de Ciências nos anos iniciais a partir da BNCC, promovido em parceria pelo Programa de Pós-Graduação Educação em Ciências/UFSM e a Secretaria Municipal de Educação de um município de pequeno porte do interior do estado do RS. Tal Programa ocorreu durante o processo de tramitação e aprovação da BNCC junto ao CONSED e desenvolveu-se por meio de nove encontros (E1, E2, E3...E9) contando com 17 inscritos (MARIANI e SEPEL, 2019a).

O púbico que compõe este artigo são nove docentes participantes do Programa de Formação Continuada e presentes nos encontros E5 e E9. A fim de manter preceitos éticos da pesquisa eles serão nominados por P.1, P.2, ...P.17. Os dados produzidos neste estudo de caso são: os Planos de Estudos das escolas nas quais os docentes atuavam no período da pesquisa, formulários constituídos no E5 e um questionário respondido no $\mathrm{E} 9$, como segue:

i) Planos de Estudos: são Documentos Oficiais das sete intuições de ensino na qual os nove docentes participantes da pesquisa estavam atuando no período do Programa de Formação. Basicamente todos os Planos de Estudos possuem a mesma organização com os dados de identificação da escola, ano para 0 qual se aplica e um quadro descrevendo as competências, habilidades, conhecimentos e valores para cada área do conhecimento. A variação ocorre em algumas habilidades elencadas pelos docentes e gestores a fim de contemplar as diferentes realidades das escolas.

ii) Formulário de análise dos Planos de Estudos das escolas: o qual contém as três Unidades Temáticas apresentadas pela BNCC para a área de Ciências da Natureza, Objetos do Conhecimento apresentados para o $4^{\circ}$ e $5^{\circ}$ ano e consequentemente as Habilidades que derivam destes Objetos do Conhecimento. Uma coluna com a questão sobre a presença nos planos de estudos da escola com as alternativas: "Já existe e já é trabalhado"; "Já existe, mas não trabalhamos neste ano" e "É novidade". E posteriormente três colunas que avaliam sobre a aplicabilidade da habilidade destacada nos níveis: "Totalmente aplicável"; "Mais ou menos aplicável" e "Pouco aplicável". Os códigos utilizados no formulário (EF04CI01, EF04CI02, EF04CI03...) referem-se aos apresentados pela BNCC (BRASIL, 2017) para as habilidades relacionadas aos Objetos do Conhecimento, as quais estão sendo investigadas nesta pesquisa. 
No formulário elencamos as Unidades Temáticas, os Objetos do Conhecimento e as Habilidades a serem desenvolvidas, os professores tinham a opção de assinalar uma das três alternativas: "J- Já consta no Plano e Estudos e já é trabalhado"; "JNT- Já consta no Plano de Estudos, mas não é trabalhado neste ano" e "N- É novidade". Após esta comparação documental, realizada pelos docentes, passamos a questioná-los em relação à aplicabilidade e desenvolvimento das habilidades elencadas, preenchendo itens do formulário de acordo com a seguinte legenda: "T: Totalmente aplicável”; "M: Mais ou menos aplicável" e "P: Pouco aplicável".

iii)Questionário: composto por cinco questões. A primeira, aberta, investiga sobre a avaliação dos docentes referentes as Unidades Temáticas e distribuição dos Objetos do Conhecimento da BNCC, a segunda, fechada, sobre a prática dos docentes perante os Objetos do Conhecimento. A terceira questão, fechada, abordou a aprendizagem dos docentes em relação às atividades propostas. As duas últimas eram questões abertas sendo que a quarta versa sobre a implementação da BNCC e a quinta sobre as contribuições, aspectos positivos. Neste estudo, abordaremos apenas as respostas referentes à questão 1.

Para a análise dos dados utilizamos a Análise de Conteúdo apresentada por Bardin (2010) a qual busca através das mensagens expressas organizar categorias de análise. Na pré-análise foi realizada a seleção, reestruturação, elaboração e apreciações preliminares da BNCC e dos sete Planos de Estudos. Por meio da exploração do material, na segunda fase da análise de conteúdo, foram constituídas as seguintes categorias: 1- Ênfase na organização da BNCC; 2- Enfoque no favorecimento da aprendizagem dos alunos; 3- Proeminência de situações práticas; 4- Evidência de metodologias para o conhecimento das Unidades Temáticas, a qual ocorreu através de um Programa de Formação Continuada. E, no tratamento dos resultados e interpretações foram realizados aprimoramentos e sistematização dos resultados a fim de torná-los válidos e significativos.

\section{Inferências e discussões}

$\mathrm{Na}$ análise dos dados estaremos expondo as aproximações e distanciamentos encontrados pelos docentes na análise comparativa entre as Unidades Temáticas 
e Objetos do Conhecimento apresentadas pela BNCC, bem como a avaliação dos docentes em relação a aplicabilidade das mesmas.

\section{Os Planos de Estudos e a BNCC: aproximações e distanciamentos}

Para melhor compreensão dos resultados, apresentamos os dados considerando, individualmente, cada uma das Unidades Temáticas Matéria e Energia, Vida e Evolução e Terra e Universo no que se refere ao $4^{\circ}$ e $5^{\underline{o}}$ anos. Desse modo, expomos a análise dos docentes em relação aos Planos de Estudos e à BNCC, e em seguida, a análise de sua aplicabilidade. No Tabela 1, por exemplo, constam informações dos docentes que atuavam no $4^{\circ}$ ano, e na Tabela 2 os que ministravam aula no $5^{\circ}$ ano, ambas referentes à Unidade Temática Matéria e Energia.

Tabela 1: Análise dos docentes em relação aos Planos de Estudos do $4^{\circ}$ ano - Matéria e Energia

\begin{tabular}{|c|c|c|c|c|}
\hline $\begin{array}{l}\text { Unidades Temática/ } \\
\text { Objetos do Conhecimento }\end{array}$ & Habilidades & $\mathrm{J}$ & JNT & $\mathrm{N}$ \\
\hline $\begin{array}{l}\text { MATÉRIA E ENERGIA } \\
\text { Misturas } \\
\text { Transformações reversíveis } \\
\text { e não reversíveis }\end{array}$ & $\begin{array}{l}\text { (EF04CI01) Identificar misturas na vida diária, } \\
\text { com base em suas propriedades físicas observá- } \\
\text { veis, reconhecendo sua composição } \\
\text { (EF04CI02) Testar e relatar transformações nos } \\
\text { materiais do dia a dia quando expostos a diferen- } \\
\text { tes condições (aquecimento, resfriamento, luz e } \\
\text { umidade) } \\
\text { (EF04CI03) Concluir que algumas mudanças } \\
\text { causadas por aquecimento ou resfriamento são } \\
\text { reversíveis (como as mudanças de estado físico } \\
\text { da água) e outras não (como o cozimento do ovo, } \\
\text { queima de papel etc }\end{array}$ & & 2 & 3 \\
\hline
\end{tabular}

Fonte: Dados da pesquisa.

Legenda: J- Já consta no Plano de Estudos e já é trabalhado; JNT- Já consta no Plano de Estudos, mas não é trabalhado neste ano e N- É novidade.

Diante do exposto, constatamos que existem divergências entre a nova organização proposta pela BNCC os Planos de Estudos adotados pelas escolas de rede municipal, pois através das análises dos docentes, respeitando diferenças nos Planos e Estudos de cada uma das instituições na qual eles estão trabalhando, detectamos que não há unanimidade nas respostas no que se refere à Unidade Temática Matéria e Energia. Esta Unidade visa construir conhecimentos a partir das primeiras 
noções sobre a matéria e os diferentes usos de energia, valorizando elementos concretos e ambientes que o cercam através dos Objetos do Conhecimento: Misturas e Transformações reversíveis e não reversíveis. Os docentes afirmam na totalidade que não desenvolvem as Habilidades EF04CI01, EF04CI02 e EF04CI03 no 4 ano, sendo que dois afirmaram que tais habilidades são dinamizadas em outros anos escolares. Três docentes afirmam que as Habilidades EF04CI01 e EF04CI02 não estão contempladas no currículo atual. Além disso, outros dois docentes destacaram que EF04CI03 não está contemplada no currículo e um docente absteve-se.

Quanto à aplicabilidade, 40\% dos docentes avaliaram que EF04CI01 é totalmente aplicável e 60\% como mais ou menos aplicável. Já nas Habilidades EF04CI02 e EF04CI03 obtivemos uma avaliação de 60\% como totalmente aplicável e $40 \%$ como mais ou menos aplicável. Nenhuma das três Habilidades apresentadas nesta Unidade Temática foi considerada "pouco aplicável”, demostrando credibilidade perante a compreensão destes conhecimentos pelos alunos do $4^{\circ}$ ano, mesmo que eles ainda não pertençam ao atual Plano de Estudo deste ano escolar nas instituições. Reiteramos a ideia de que a Unidade Temática Matéria e Energia, no $4^{\circ}$ ano, se distancia muito da realidade dos Planos de Estudos hora analisados, necessitando de uma significativa adaptação para que as habilidades apresentadas pela BNCC sejam incorporadas ao currículo escolar.

No panorama apresentado pelos docentes do $5^{\circ}$ ano (Tabela 2), constatamos que na Unidade Temática: Matéria e Energia o Objeto do Conhecimento Propriedades físicas dos materiais, através da Habilidade EF05CI01, não pertence ao currículo atual, segundo todos os respondentes. No que se refere aos Objetos de Conhecimento de Ciclo Hidrológico, Consumo Consciente e Reciclagem, Habilidades EF05CI02, EF05CI03, EF05CI04, conforme os docentes, já são trabalhados no $5^{\circ}$ ano e são totalmente aplicáveis, conforme $100 \%$ dos respondentes, e na sua maioria na Habilidade EF05CI05. 
Tabela 2: Análise dos docentes em relação aos Planos de Estudos do $5^{\circ}$ ano - Matéria e Energia

\begin{tabular}{|c|c|c|c|c|}
\hline $\begin{array}{c}\text { Unidades Temática/ } \\
\text { Objetos do Conhecimento }\end{array}$ & Habilidades & $J$ & JNT & $\mathrm{N}$ \\
\hline $\begin{array}{l}\text { MATÉRIA E ENERGIA } \\
\text { Propriedades físicas dos } \\
\text { materiais } \\
\text { Ciclo hidrológico } \\
\text { Consumo consciente } \\
\text { Reciclagem }\end{array}$ & $\begin{array}{l}\text { (EF05CI01) Explorar fenômenos que eviden- } \\
\text { ciem propriedades físicas dos materiais- como } \\
\text { densidade, condutibilidade térmica e elétrica, } \\
\text { respostas e forças magnéticas, solubilidade, } \\
\text { respostas a forças mecânicas (dureza, elastici- } \\
\text { dade etc.) entre outras. } \\
\text { (EF05CI02) Aplicar os conhecimentos sobre as } \\
\text { mudanças de estado físico da água para explicar } \\
\text { o ciclo hidrológico e analisar suas implicações } \\
\text { na agricultura, no clima, na geração de energia, } \\
\text { no provimento de água potável e no equilíbrio } \\
\text { dos ecossistemas regionais (ou locais). } \\
\text { (EF05CI03) Selecionar argumentos que justifi- } \\
\text { quem a importância da manutenção da cobertu- } \\
\text { ra vegetal para a manutenção do ciclo da água, } \\
\text { preservação dos solos, dos cursos de água e da } \\
\text { qualidade do ar atmosférico. } \\
\text { (EF05CI04) Identificar os principais usos da } \\
\text { água e de outros materiais nas atividades coti- } \\
\text { dianas e discutir os possíveis problemas decor- } \\
\text { rentes desses usos. } \\
\text { (EF05CI05) Construir propostas coletivas para } \\
\text { um consumo mais consciente, descarte ade- } \\
\text { quado e ampliação de hábitos de reutilização e } \\
\text { reciclagem de materiais consumidos na escola } \\
\text { elou na vida cotidiana. }\end{array}$ & 3 & 1 & 4 \\
\hline
\end{tabular}

Fonte: Dados da Pesquisa.

Legenda: J- Já consta no Plano de Estudos e já é trabalhado; JNT- Já consta no Plano de Estudos, mas não é trabalhado neste ano e $\mathrm{N}$ - É novidade.

Em relação aplicabilidade da Habilidade EF05CI01, 75\% dos docentes avaliaram como mais ou menos aplicáveis e $25 \%$ como pouco aplicáveis. Destacamos que esta habilidade explora propriedades físicas dos materiais. A Habilidade EF05CI05 que enfatiza o desenvolvimento de propostas coletivas para o consumo consciente obteve $50 \%$ das avaliações como totalmente aplicáveis e 50\% mais ou menos aplicáveis. De forma geral, percebemos, nesta unidade temática, há um distanciamento entre a realidade hora apresentada pelos Planos de Estudos e o minimamente preconizado pela BNCC, no que tange as habilidades do $4^{\circ}$ ano para a área das Ciências da Natureza e uma aproximação maior ao do $5^{\circ}$ ano. 
Como já foi destacado, esta unidade busca potencializar a compreensão da origem, utilização e processamento de recursos naturais e energéticos, que são saberes balizadores para conhecimentos a serem abordados nos outros anos escolares. É importante que estes Objetos do Conhecimento sejam explorados dentro de uma contextualização histórica e social desenvolvendo-se através de práticas investigativas e de uma linguagem científica, conforme Franco e Mundoford (2018), mesmo a BNCC na última versão, não enfocando este aspecto.

A Unidade Temática de Vida e Evolução no $4^{\circ}$ ano estuda questões relacionadas aos seres vivos englobando características e necessidades naturais e sociais, a totalidade os respondentes afirmaram que os Objetos do Conhecimento: Cadeias alimentares simples e microrganismos não pertencem ao grupo de saberes abordados no $4^{\circ}$ ano, incluindo suas Habilidades (EF04CI04, EF04CI05, EF04CI06, EF04CI07, EF04CI08). Ao analisar tal unidade, constatamos que os docentes divergem em relação a seus entendimentos sobre se conhecimentos são ou não explorados em outros anos escolares, já que, conforme seus entendimentos não constam no currículo escolar do $4^{0}$ ano (Tabela 3 ).

Tabela 3: Análise dos docentes em relação aos Planos de Estudos do $4^{\circ}$ ano - Vida e Evolução

\begin{tabular}{l|l|l|l}
\hline \multicolumn{1}{c|}{$\begin{array}{c}\text { Unidades Temática/ } \\
\text { Objetos do Conhecimento }\end{array}$} & \multicolumn{1}{|c|}{ Habilidades } & JNT & N \\
\hline $\begin{array}{l}\text { VIDA E EVOLUÇÃO } \\
\text { Cadeiras alimentares sim- } \\
\text { ples } \\
\text { Microrganismos }\end{array}$ & $\begin{array}{l}\text { (EF04CI04) Analisar e construir cadeias alimentares } \\
\text { simples, reconhecendo a posição ocupada pelos se- } \\
\text { res vivos nessas cadeias e o papel do Sol como fonte } \\
\text { de energia na produção de alimentos } \\
\text { (EF04CI05) Descrever e destacar semelhanças e di- } \\
\text { ferenças entre o ciclo da matéria e o fluxo de energia } \\
\text { entre componentes vivos e não vivos de um ecossis- } \\
\text { tema }\end{array}$ & $\begin{array}{l}\text { (EF04CI06) Relacionar a participação de fungos e } \\
\text { bactérias no processo de decomposição, reconhe- } \\
\text { cendo a importância ambiental desse processo. } \\
\text { (EF04CI07) Verificar a participação de microrganis- } \\
\text { mos na produção de alimentos, combustíveis, medi- } \\
\text { camentos e outros. } \\
\text { (EF04CI08) Propor, a partir do conhecimento das for- } \\
\text { mas de transmissão de alguns microrganismos (vírus, } \\
\text { bactérias, protozoários) atitudes e medidas adequa- } \\
\text { das para prevenção de doenças a eles associadas. }\end{array}$ & 2 \\
\hline
\end{tabular}

Fonte: Dados da pesquisa.

Legenda: J- Já consta no Plano de Estudos e já é trabalhado; JNT- Já consta no Plano de Estudos, mas não é trabalhado neste ano e N- É novidade. 
Quanto à aplicabilidade, $60 \%$ dos docentes avaliaram que a Habilidade EF04CI04 é totalmente aplicável, 20\% mais ou menos aplicável e $20 \%$ pouco aplicável, já na Habilidade EF04CI05, 20\% totalmente aplicável, 60\% mais ou menos aplicável e 20\% pouco aplicável. Nas Habilidades EF04CI06 e EF04CI07, 20\% dos docentes avaliaram como totalmente aplicável e $60 \%$ como mais ou menos aplicável, $20 \%$ optou por não responder. Já na Habilidade EF04CI08 constatamos 80\% dos docentes a consideram como totalmente aplicável e $20 \%$ não opinaram. Nesta Unidade Temática percebemos que, no $4^{\circ}$ ano, as habilidades que apresentaram maior credibilidade de aplicação para os docentes foram EF04CI04 e EF04CI08, que se referem, respectivamente, as cadeias alimentares e as formas de transmissão de alguns microrganismos, prevenção e doenças.

A análise dos docentes do $5^{\mathrm{o}}$ ano (Tabela 4) quanto a Unidade Temática Vida e Evolução, nos Objetos de Conhecimento de Nutrição do organismo, Hábitos alimentares, Integração entre sistema digestório, respiratório e circulatório revela que apenas um deles identificou a Habilidade EF05CI09 contemplada em seu Plano de Estudos. As demais não foram observadas nos planos atuais, sendo que a maioria dos docentes afirmou que EF05CI06, EF05CI07, EF05CI08 são trabalhadas em outros anos escolares e EF05CI09 não foi reconhecida no currículo escolar, pela maioria dos docentes.

Tabela 4: Análise dos docentes em relação aos Planos de Estudos do $5^{\circ}$ ano - Vida e Evolução.

\begin{tabular}{|c|c|c|c|c|}
\hline $\begin{array}{l}\text { Unidades Temática/ } \\
\text { Objetos do Conhecimento }\end{array}$ & Habilidades & $\mathrm{J}$ & JNT & $\mathrm{N}$ \\
\hline $\begin{array}{l}\text { VIDA E EVOLUÇÃO } \\
\text { Nutrição do organismo } \\
\text { Hábitos alimentares } \\
\text { Integração entre os siste- } \\
\text { mas digestório, respiratório } \\
\text { e circulatório }\end{array}$ & $\begin{array}{l}\text { (EF05CI06) Selecionar argumentos que justifiquem por que os } \\
\text { sistemas digestório e respiratório são considerados correspon- } \\
\text { sáveis pelo processo de nutrição do organismo, com base na } \\
\text { identificação das funções desses sistemas. } \\
\text { (EF05CI07) Justificar a relação entre o funcionamento do sis- } \\
\text { tema circulatório, a distribuição dos nutrientes pelo organismo } \\
\text { e a eliminação dos resíduos produzidos. } \\
\text { (EF05Cl08) Organizar um cardápio equilibrado com base nas } \\
\text { características dos grupos alimentares (nutrientes e calorias) } \\
\text { e nas necessidades individuais (atividades realizadas, idade, } \\
\text { sexo etc.) para a manutenção da saúde no organismo. } \\
\text { (EF05CI09) Discutir a ocorrência dos distúrbios nutricionais } \\
\text { (como obesidade) entre crianças e jovens, a partir da análise } \\
\text { de seus hábitos (tipos de alimento ingerido, prática de ativida- } \\
\text { de física etc.). }\end{array}$ & 1 & 3 & 1 \\
\hline
\end{tabular}

Fonte: Dados da pesquisa.

Legenda: J- Já consta no Plano de Estudos e já é trabalhado; JNT- Já consta no Plano de Estudos, mas não é trabalhado neste ano e N- É novidade. 
Quanto a aplicabilidade, EF05CI06, EF05CI07, EF05CI08 foram avaliadas por $50 \%$ dos docentes como totalmente aplicáveis e 50\% como mais ou menos aplicáveis. Já a habilidade EF05CI09 obteve 25\% das avaliações como totalmente aplicável, $50 \%$ mais ou menos aplicável e 25\% pouco aplicável. Esta Unidade Temática constitui-se em fonte importante de saberes, pois engloba os conhecimentos da área de biologia a partir do estudo dos os seres vivos, desde suas características e necessidades, processo evolutivo, interação entre os seres vivos e principalmente a que o ser humano estabelece entre si e com os demais seres vivos e elementos não vivos do ambiente, a preservação da biodiversidade até o aprendizado sobre aspectos relativos à saúde individual e coletiva, inclusive no âmbito das políticas públicas. Assim, seu trabalho dever ser vinculado a realidade dos alunos e as consequências dele são diretas na qualidade de vida do planeta.

A Unidade Temática Terra e Universo, enfatiza conhecimentos que buscam aguçar a curiosidade pelos fenômenos naturais e desenvolver o pensamento espacial através da observação e análise dos corpos celestes. Essa Unidade Temática contém como Objetos do Conhecimento: Pontos Cardeais e Calendários, fenômenos cíclicos e cultura. Ao analisar as respostas dos docentes do $4^{\circ}$ ano constatamos que uma docente afirmou que a Habilidade EF04CI010 já está contemplada e desenvolvida no $4^{\circ}$ ano, os demais, afirmaram que estes conhecimentos são desenvolvidos em outros anos escolares. As Habilidades EF04CI09 e EF04CI011 também são desenvolvidas em outros anos escolares, segundo a maioria dos docentes (Tabela 5).

Tabela 5: Análise dos docentes em relação aos Planos de Estudos do $4^{\circ}$ ano - Terra e Universo.

\begin{tabular}{|c|c|c|c|c|}
\hline $\begin{array}{l}\text { Unidades Temática/ } \\
\text { Objetos do Conhecimento }\end{array}$ & Habilidades & $\mathrm{J}$ & JNT & $\mathrm{N}$ \\
\hline $\begin{array}{l}\text { TERRA E UNIVERSO } \\
\text { Pontos Cardeais } \\
\text { Calendários, fenômenos } \\
\text { cíclicos e cultura }\end{array}$ & $\begin{array}{l}\text { (EF04CI09) Identificar os pontos cardeais, com base no re- } \\
\text { gistro de diferentes posições relativas do Sol e da sombra de } \\
\text { uma vara (gnômon). } \\
\text { (EF04CI010) Comparar e explicar as diferenças encontradas } \\
\text { na indicação dos pontos cardeais resultante da observação } \\
\text { das sombras de uma vara (gnômon) e por meio de uma bús- } \\
\text { sola. } \\
\text { (EF04CI011) Associar os movimentos cíclicos da Lua e da } \\
\text { Terra a períodos de tempo regulares e ao uso desse conhe- } \\
\text { cimento para a construção de calendários em diferentes cul- } \\
\text { turas }\end{array}$ & 1 & 4 & 1 \\
\hline
\end{tabular}

Fonte: Dados da pesquisa.

Legenda: J- Já consta no Plano de Estudos e já é trabalhado; JNT- Já consta no Plano de Estudos, mas não é trabalhado neste ano e N- É novidade. 
Quanto a aplicabilidade, 60\% dos docentes avaliaram EF04CI09 e EF04CI011 como totalmente aplicáveis e $40 \%$ como mais ou menos aplicáveis, já na Habilidade EF04CI010 obtivemos 100\% dos respondentes considerando-a como totalmente aplicável, a qual estimula a aprendizagem dos pontos cardeais por meio do uso da vara de gnômon e da bússula.

Quanto a Unidade Temática: Terra e Universo, em relação à EF05CI010 e EF05CI011, três docentes apontaram que elas não estão contempladas nos planos de estudos de suas escolas, e um docente considerou positivamente, comprovando a diversidade de Planos de Estudos na mesma rede de ensino. Já a Habilidade EF05CI011, já conta no currículo do $5^{\circ}$ ano, segundo dois docentes e a Habilidade EF05CI011 também, de acordo com um docente, sendo que outros dois afirmaram que estas duas últimas habilidades estão contempladas em outros anos escolares (Tabela 6).

Tabela 6: Análise dos docentes em relação aos Planos de Estudos do $4^{\circ}$ ano - Terra e Universo.

\begin{tabular}{|c|c|c|c|c|}
\hline $\begin{array}{c}\text { Unidades Temática/ } \\
\text { Objetos do Conhecimento }\end{array}$ & Habilidades & $\mathrm{J}$ & JNT & $\mathrm{N}$ \\
\hline $\begin{array}{l}\text { TERRA E UNIVERSO } \\
\text { Constelações e mapas } \\
\text { celestes } \\
\text { Movimentação de rotação } \\
\text { da Terra } \\
\text { Periodicidade das fases da } \\
\text { Lua } \\
\text { Instrumentos óticos }\end{array}$ & $\begin{array}{l}\text { (EF05CI010) Identificar algumas constelações no } \\
\text { céu, com apoio de recursos, como mapas celestes } \\
\text { e aplicativos, entre outros, e os períodos do ano } \\
\text { em que elas são visíveis no início da noite. } \\
\text { (EF05Cl011) Associar o movimento diário do Sol e } \\
\text { demais estrelas do céu ao movimento de rotação } \\
\text { da Terra. } \\
\text { (EF05Cl012) Concluir sobre a periodicidade das } \\
\text { fases da Lua, com base na observação e no regis- } \\
\text { tro das formas aparentes da Lua no céu ao longo } \\
\text { de, pelo menos, dois meses. } \\
\text { (EF05Cl013) Projetar e construir dispositivos para } \\
\text { observação à distância (luneta, periscópio etc.) } \\
\text { para observação ampliada de objetos (lupas, mi- } \\
\text { croscópios) ou para registro de imagens (máqui- } \\
\text { nas fotográficas) e discutir usos sociais desses } \\
\text { dispositivos. }\end{array}$ & 1 & 2 & 1 \\
\hline
\end{tabular}

Fonte: Dados da Pesquisa.

Legenda: J- Já consta no Plano de Estudos e já é trabalhado; JNT- Já consta no Plano de Estudos, mas não é trabalhado neste ano e N- É novidade.

As Habilidades EF05CI011 e EF05CI015, são totalmente aplicáveis por 50\% dos docentes e mais ou menos aplicáveis pelos demais. Já na Habilidade EF05CI011, 
que explora o movimento diário do Sol e demais estrelas ao movimento de rotação da Terra, é tida como totalmente aplicável por $100 \%$ dos docentes e a Habilidade EF05CI012, que versa sobre as fases da lua, como totalmente aplicável por $75 \%$ dos respondentes e mais ou menos aplicável pelos outros professores. Desta forma, constatamos que das onze Habilidades apresentadas para a área de Ciências da Natureza no $4^{\circ}$ ano, apenas um docente em uma Habilidade afirma que ela já compõe a lista de saberes deste período escolar. Esse dado nos leva a constatar que os Planos de Estudos das escolas nas quais os docentes participantes desta pesquisa atuam não são compatíveis com a BNCC e que deverão sofrer muitas alterações, a fim de que os direitos de aprendizagem preconizados pela BNCC sejam efetivados conforme o que fica instituído pela Resolução do CNE/CP № 2, de 22 de dezembro de 2017.

Destacamos que conforme Menegolla e Sant Anna (2014), a escola pode e deve elaborar os seus planos curriculares, partindo da orientação dada pela lei ou pelos sistemas, com finalidade de atender as características locais e as necessidades da comunidade, garantindo a oferta de saberes comuns a todos e complementado com conhecimentos específicos de cada realidade. É importante que os gestores e docentes estejam conscientes da importância deste processo de reformulação curricular de todo o país desencadeado pela BNCC, a fim de que seja organizado em todas as redes de ensino e escolas, momentos adequados para o diagnóstico da realidade, estudos, reflexões e um confrontamento entre o currículo vigente o novo currículo a ser implementado. Estes momentos precisam ser bem planejados dentro de uma metodologia que possibilite a participação, a interação entre pares a determinação pelos próprios docentes das formas de operacionalização mais adequadas para a realidade de cada instituição escolar.

Cabe destacar também que, não trata-se apenas da reformulação dos Planos de Estudos e sim de uma reformulação curricular da escola, enfatizada por Sacristán (1998), como uma ação complexa e que envolve elementos que influenciam e são influenciados pelos docentes, pelas políticas educacionais, entre outras, expressas através dos documentos oficiais que necessitam ser revistos como: Projeto Pedagógico, Regimentos Escolares e que envolve muito mais do que apenas os objetos do conhecimento a serem desenvolvidos nas aulas.

É indispensável acima de tudo tempo, para que os gestores e docentes conheçam, reflitam e apropriem-se da BNCC, e que a partir dela consigam mobilizar toda a 
comunidade escolar para esta compreensão, pois a reformulação curricular não pode acontecer de forma fechada, e sim por meio da participação de todos, principalmente no que se refere ao Projeto Pedagógico e aos Regimentos Escolares. O próprio texto da BNCC afirma que essas decisões resultam de um processo de envolvimento e participação das famílias e da comunidade.

Em relação à avaliação dos docentes quanto a aplicabilidade das referidas Habilidades, constatamos índices positivos, que oscilam em sua maioria entre totalmente aplicável e mais ou menos aplicável ao longo das três unidades temáticas da área de Ciências da Natureza do $4^{\circ}$ ano. Estes dados podem demostrar que as habilidades apresentadas pela BNCC já pertencem ao rol de saberes que destes docentes e são pertinentes ao contexto de aprendizagem de seus alunos.

Já, no $5^{o}$, concluímos que existe uma aproximação mais significativa entre a BNCC e os Planos de Estudos vigentes, porém a maioria dos Objetos de Conhecimento são desvinculados deste ano escolar, apontados pelos docentes que se encontram em outros anos escolares. Conforme a BNCC Brasil (2017), a política apresentada visa superar as fragmentações disciplinares promovendo processos educativos que organizem os saberes a serem implementadas em cada ano escolar, assegurando que os direitos de aprendizagem se efetivem em todos os ambientes escolares do país. Assim, o currículo comum de todas as escolas do país, terão minimamente os mesmos objetos do conhecimento e habilidades a serem trabalhados, complementados pela parte diversificada de cada região e realidade escolar. Na análise dos docentes do $5^{\circ}$ ano relacionadas a aplicabilidade, tivemos uma regularidade na maioria das respostas alternando respostas entre totalmente e mais ou menos aplicável, exceto na habilidade EF05CI09, do Objeto de Conhecimento de Vida e Evolução.

Conforme destaca Sacristán (1998), estamos vivenciando na prática uma nova constituição currículo, com o currículo prescrito através da BNCC e suas normatizações, o currículo apresentado, através das novas coleções de livros didáticos que realizam a transposição dos Objetos do Conhecimento em materiais didáticos, o currículo moldado que são os Planos de Estudos ou ensino elaborados pelos docentes a serem implementados, o currículo em ação, e realizado que serão dinamizados pelos docentes assim que os planos forem aprovados e implementados pelas redes e o currículo avaliado, através de sistemas de avaliação de larga escala, que buscam mensurar os avanços e estabelecer índices de classificação para as redes e as instituições. 
Fica evidente o protagonismo docente nas dimensões de currículo moldado, currículo em ação e currículo realizado, os quais terão oportunidade de imprimir sua identidade e da sua comunidade, trazendo esperança de que não tenhamos apenas uma reprodução do que está prescrito nos documentos legais. Os docentes precisam ocupar este espaço, fazer valer suas propostas, irem além do mínimo estabelecido como "direitos de aprendizagem".

\section{As Unidades Temáticas e a distribuição dos conteúdos na avaliação dos docentes}

Partimos então para investigar, junto ao grupo de docentes sobre suas percepções a respeito da nova organização da área de ciências da natureza dentro das Unidades Temáticas através da questão aberta que investigou junto aos docentes se: $E m$ sua avaliação, as Unidades Temáticas: Matéria e Energia, Vida e Evolução e Terra e Universo favorecem a distribuição dos conteúdos a serem trabalhados de maneira mais organizada e sequencial, por quê? Categorizamos as respostas agrupando por aproximação na ênfase dada para facilitar a análise dentro das seguintes categorias:

A categoria 1 comporta as respostas que apresentaram ênfase na organização da BNCC:

Acredito que sim, pois de acordo com a apresentação da BNCC- Ciências da Natureza podemos perceber que há uma sequência que se complementa e aprofunda durante os ciclo ou anos, ou seja, há uma organização. (Questionário 3, P.8)

Sim, dessa forma há uma sequência que se complementa, ou seja, uma organização. (Questionário 3. P.9)

Nesta categoria, os docentes afirmam que as Unidades Temáticas organizaram os objetos do conhecimento a serem trabalhados e focam ainda na ideia de continuidade dos mesmos, já que perpassam todos os anos escolares nesta área do conhecimento, apresentando de forma sequencial e gradual as habilidades a serem desenvolvidas. Segundo a BNCC, para cada componente curricular ficam estabelecidas as Unidades Temáticas que definem uma organização para os Objetos do Conhecimento (conteúdos, conceitos e processos) ao longo de todo o Ensino Fundamental, de forma possibilitar o desenvolvimento dos processos de aprendizagem de forma progressiva. [...] "essas habilidades mobilizam conhecimentos conceituais, linguagens e alguns 
dos principais processos, práticas e procedimentos de investigação envolvidos na dinâmica da construção de conhecimentos na ciência" (BRASIL,2017, p. 328)

Segundo Franco e Munford (2018) e Compiani (2018), o texto da BNCC sofreu grandes mudanças na organização e modo como o conhecimento foi estruturado durante seu período de tramitação. A primeira versão apresentava seis Unidades do Conhecimento: materiais, substâncias e processo, ambiente, recursos e responsabilidades, bem- estar e saúde, Terra, constituição e movimento, vida: constituição e reprodução, sentidos: percepções e interações. Já a terceira versão, organiza-se através de três Unidades Temáticas, sem uma justificativa clara de como foram realizadas estas mudanças. Na visão destes mesmos autores, as Unidades Temáticas acabaram por atribuir um destaque menor as questões sociais e as interlocuções dos saberes ao cotidiano dos alunos.

As respostas dos docentes direcionam-se a versão atual, provavelmente eles não se detiveram a estudos aprofundados de todas as áreas do conhecimento ao longo do processo de tramitação, por questões diversas, o que acaba por gerar uma certa conformidade com o documento atual e prejudicar a análise crítica sobre o mesmo.

A categoria 2 concentra as respostas dos docentes que expressaram enfoque no favorecimento da aprendizagem dos alunos.

Sim, porque uma vai complementando a outra e a sequência de um ano para o outro também favorece o entendimento da aprendizagem. (Questionário 3. P. 11)

Com certeza, nos favorece ao realizar os planos diários, de forma que a sequência didática seja significativa para o aprendizado de cada aluno. (Questionário 3. P.10)

Sim uma forma bem organizada e dando sequência aos conteúdos, o que facilita a compreensão e o aprendizado. (Questionário 3. P.5)

Nesta categoria os docentes afirmam favorecimento na aprendizagem e compreensão dos alunos a partir de uma sequência clara que está explicitada na BNCC, deixando evidente a percepção do encadeamento entre os objetos do conhecimento de um período letivo para o outro. Porém, o texto da BNCC, Brasil (2017) ressalta que a organização das habilidades nos agrupamentos apresentados é apenas um dos arranjos possíveis de serem efetivados e que há liberdade para as instituições determinarem novas organizações.

É evidente que uma organização e um encadeamento favorecem a aprendizagem do aluno e o próprio desenvolvimento da lógica do planejamento desenvolvida pelos 
docentes, o que com certeza impactará sobre a aprendizagem dos alunos, porém temos que destacar a necessidade de trabalharmos para além do que está exposto na BNCC, precisamos trabalhar estes objetos do conhecimento de forma mais ampla e integrada com as outras áreas.

Para Franco e Munford (2018) a BNCC privilegia aspectos conceituais da área de ciências, prejudicando a articulação entre os diferentes elementos que compõe a construção da ciência. Tornando a visão de aprendizagem diferente da preconizada pelos estudiosos desta área que enfatiza a Alfabetização Científica, a qual busca o desenvolvimento do senso crítico dos estudantes e sua capacidade de refletir sobre tomada de decisões, estabelecendo relações entre ciência, tecnologia, problemas sociais e ambientais.

Desta forma, percebemos que a BNCC deveria apresentar mais avanços ao ensino da área de ciências, condizentes com o próprio conceito de "letramento cientifico" o qual apresenta nas páginas iniciais da seção de Ciências Naturais, mas que não se concretizam na relação de habilidades apresentadas, trazendo além da ênfase nos conceitos e nas habilidades práticas um enfoque mais cientifico, social, tecnológico e ambiental destes conhecimentos, com vistas a potencializar os reflexos do ensino escola na vida e na busca pela qualidade de vida dos alunos e suas comunidades.

A categoria 3 concentra as respostas que expressaram valorização nas situações práticas.

Sim, principalmente tendo a teoria e aplicação de maquetes, experiências, etc. (Questionário 3. P.2)

Sim, as unidades temáticas favorecem na organização do material de apoio, no planejamento dos temas de modo que exista uma sequência de propostas visando a construção do conhecimento de forma prática e explicativa. (Questionário 3. P.4)

Sim, porque a BNCC nos fornece a sequência de conteúdos a serem trabalhados de forma prática com os alunos. (Questionário 3. P.13)

Nesta categoria agrupamos respostas que valorizaram as situações práticas, explicitadas através das habilidades apresentadas pelo texto da BNCC, as quais tem o objetivo de estabelecer a apropriação prática (saber fazer) do aluno sobre um determinado objeto do conhecimento. Assim, este documento, além de listar os conhecimentos a serem trabalhados, demarca qual a aplicabilidade deve ser ensinada minimamente aos alunos. 
É importante que a área de Ciências da Natureza seja trabalhada na perspectiva de ensino por investigação (CARVALHO, 2011 e 2013) através do desenvolvimento de Sequências de Ensino Investigativas (SEI) com os alunos participando ativamente de atividades que favoreçam as habilidade de observação, experimentação, comunicação e debate de fatos e ideias, para que ocorram oportunidades de construção do conhecimento científico.

As habilidades auxiliam os docentes no estabelecimento de objetivos e metodologias utilizadas em seus planejamentos, pois são determinações explícitas de onde se deve chegar, acreditamos que por esse motivo os docentes tenham enfatizado a questão prática da BNCC, porém cabe-nos destacar que este aspecto também pode se caracterizar como reducionista e doutrinador.

Os docentes necessitam dominar os conteúdos para além das habilidades determinadas pelo documento, é necessário personalizar as práticas, imprimir as caraterísticas e necessidades do público com o qual e se trabalha. Ir sobretudo além, mostrando aos alunos novas aplicabilidades do saber.

A categoria 4 foi composta pelas respostas as quais os docentes enfatizaram $a$ metodologia utilizada para o conhecimento das unidades temáticas, a qual ocorreu através de um programa de formação continuada.

Sim, porque os conteúdos partiram da prática, facilitando o entendimento e despertando o interesse dos cursistas. (Questionário 3. P.14)

Sim, pois os conteúdos foram mostrados de maneira lúdica e prática, além de serem bem explicadas com fácil entendimento. (Questionário 3. P.17)

Sim, o curso foi muito significativo e gratificante, pois proporcionou de forma criativa e dinâmica os conteúdos a serem trabalhados de maneira organizada e sequencial com os nossos educandos. Foi excelente as experiências práticas que aprendemos. (Questionário 3. P.3)

As unidades temáticas favorecem a construção de saberes pelo docente devido a mediação, organização de materiais lúdicos e criativos disponibilizados na formação. (Questionário 3. P.6)

Nesta categoria ficam evidentes as marcas deixadas pelo programa de formação continuada no qual os docentes participaram chamado: O Ensino de Ciências nos anos iniciais a partir da BNCC, o qual, desenvolveu-se dentro de uma metodologia reflexiva e colaborativa seguindo as ideias de Nóvoa (2009), desenvolveu inúmeras situações de aprendizagem em 42 horas de trabalho. 


\section{Conclusões}

Ao analisarmos as tabelas percebemos que há uma grande divergência entre os Objetos do Conhecimentos elencados pela BNCC e os Planos de Estudos das escolas em vigência durante a realização da pesquisa, há um trabalho complexo a ser desenvolvido, porém pela avaliação dos docentes em relação a estes conhecimentos que devem ser inseridos, na sua maioria são totalmente aplicáveis ou mais ou menos aplicáveis junto aos anos nos quais estão distribuídos. Os distanciamentos e aproximações entre os currículos escolares a e os arranjos propostos pela BNCC apresentam variabilidade de acordo com o ano escolar e unidade temática no qual se aplicam, bem como de acordo com a realidade dos Planos de estudos de cada instituição de ensino.

Na área de Ciências da Natureza, percebemos que a BNCC apresenta uma ênfase ao letramento científico e ao desenvolvimento de através de uma abordagem investigativa da área, privilegiando aspectos conceituais em detrimento dos contextuais. Se faz necessário um estudo por parte dos docentes a fim de que construam seus currículos com o disposto na BNCC e realizem as complementações necessárias a fim de que o Ensino de Ciências seja abordado de forma histórica, contextualizada e com linguagem científica, trazendo perspectivas de crescimento e evolução a sociedade.

É importante destacarmos que estamos em uma fase importante da educação brasileira, as normatizações vigentes estão mobilizando reformas curriculares amplas em todas as redes de ensino, necessitando de um grande esforço de toda a comunidade escolar para que tenhamos qualidade nas transformações propostas, temos uma série de documentos que fundamentam e organizam os processos educacionais como Projeto Pedagógico, Regimento Escolar, Planos de Estudos que precisam ser reelaborados de maneira participativa e comprometida.

Este artigo apresentou apenas um estudo sobre os olhares e entendimentos dos docentes no que tange a nova política educacional, apontamos a necessidade de mais pesquisas que investiguem este tema a fim de que consigamos monitorar sua implementação junto aos currículos escolares e seus possíveis impactos no sistema nacional de educação. 


\section{Teaching views: characterization of science teaching in a municipal school system before the BNCC}

\section{Abstract}

This article aims to analyze the understanding of 4th and 5th grade elementary school teachers regarding the curricular organization of the Natural Sciences Area at BNCC and the Study Plans of the schools of the municipal network in which they work, considering the Thematic Units, the Knowledge Objects and Skills. This is a qualitative research in the form of case study, involving nine teachers working in the 4th and 5th year of a municipal network in the state of RS. In the production of data are considered the principles of content analysis and are taken Study Plans from seven schools, an evaluation form consisting of eleven items for the fourth grade and thirteen for the fifth grade and a questionnaire consisting of three open questions and two closed, involving information on the BNCC Study Plans and Knowledge Objects (BRAZIL, 2017), both completed by the research participants during a continuing education program. The theoretical contributions that support the analysis are, besides the BNCC itself (BRAZIL, 2017), Sacristán $(1995,1998,2013)$, Vasconcellos (2014) and Menegolla and Sant Anna (2014), in relation to teaching planning, and Carvalho (2011, 2013), Franco and Munford (2018) and Compiani (2018), regarding the teaching of Natural Sciences. As results, there are divergences between the Study Plans of the investigated schools regarding the Knowledge and Skills Objects presented by the $\mathrm{BNCC}$, but most teachers evaluate that the precepts contained in the BNCC may be applicable in their classes. Regarding the way the Objects of Knowledge are arranged, the teachers highlight the organization of Thematic Units, the emphasis given to practical activities and the favoring of learning and understanding of knowledge.

Keywords: Educational Policies; Curriculum; Science teaching.

\section{Referências}

BARDIN, Laurence. Análise de conteúdo. 4. ed. Lisboa: Edições70, 2010.

BRASIL. Conselho Nacional de Educação. Resolução CNE/CP no 2, de 22 de dezembro de 2017 - Institui e orienta a implantação da Base Nacional Comum Curricular, a ser respeitada obrigatoriamente ao longo das etapas e respectivas modalidades no âmbito da Educação Básica. Disponível em: <http://portal.mec.gov.br/index.php?option=com_docman\&view=download\&alias=79631-rcp002-17-pdf\&category_slug=dezembro-2017-pdf\&Itemid=30192> Acesso em: 11 de julho 2018.

BRASIL. Ministério de Educação. Base Nacional Comum Curricular. Brasília. Distrito Federal. 2017.Disponível em:< http://basenacionalcomum.mec.gov.br/> Acesso em: 13 de julho de 2018.

BRASIL. Ministério da Educação. Lei de Diretrizes e Bases da Educação Nacional no 9394/1996. Brasília. 1996. Disponível em: < http://www.planalto.gov.br/ccivil_03/leis/19394.htm>. Acesso em 10 de abril de 2018.

BRASIL. Presidência da República. Lei no 12.796, de 4 de abril de 2013. Altera a Lei nº 9.394, de 20 de dezembro de 1996, que estabelece as diretrizes e bases da educação nacional, para dispor sobre a formação dos profissionais da educação e dar outras providências. Diário Oficial da 
União. Disponível em: <http://www.planalto.gov.br/ccivil_03/_Ato2011-2014/2013/Lei/L12796. htm>. Acesso em: jan. 2018.

BRASIL. Presidência da República. Lei no 13.415, de 16 de fevereiro de 2017. Altera a Lei no 9.394, de 20 de dezembro de 1996, altera o FUNDEB. Diário Oficial da União. Disponível em: https://www2.camara.leg.br/legin/fed/lei/2017/lei-13415-16-fevereiro-2017-784336-publicacaooriginal-152003-pl.html. Acesso em: 10 de março de 2017.

BRASIL. Ministério da Educação. Portaria 1.570 de 20 de dezembro de 2017. Homologa o Parecer CNE/CP no 15/2017 e dá outras providências. Disponível em: <https://abmes.org.br/arquivos/ legislacoes/Port-MEC-1570-2017-12-20.pdf>. Acesso em: 18 jan. 2018.

BRASIL. Ministério da Educação. Portaria 592 de 17 de junho de 2015. Institui Comissão de Especialistas para a Elaboração de Proposta da Base Nacional Comum Curricular. Disponível em: <http://www.editoramagister.com/legis_26906831_PORTARIA_N_592_DE_17_DE_JUNHO_ DE_2015.aspx>. Acesso em: 12 fev. 2018.

CARVAlHO, Ana Maria Pessoa. A interreação entre Didática das Ciências e a Prática de Ensino. In: SELLES, Sandra Escovedo e FERREIRA, Marcia Serra (Orgs) Formação Docente em Ciências: Memórias e Práticas. Niterói: Eduff, 2003.

CARVALHO, Anna Maria Pessoa de e GIL-PÉREZ, Daniel. (ORG), Formação de professores de ciências: tendências e inovações. 10 ed. São Paulo: Cortez, 2011,

CARVALHO, Anna Maria Pessoa de. (ORG), Ensino de Ciências por investigação: condições para implementação em sala de aula. São Paulo: CENGAGÉ LEARNING, 2013.

COMPIANI, Maurício. Comparações entre a BNCC atual e a versão da consulta ampla, item Ciências da Natureza. Ciências em Foco, v. 11, n. 1, p. 91-106, 2018.

FRANCO, Luiz Gustavo e MUNFORD, Danusa. Reflexões sobre a Base Nacional Comum Curricular: Um olhar da área de Ciências da Natureza. Revista Horizontes, v. 36, n. 1, p. 158-170, jan./abr. 2018.

FLÔR, Cristhiane Carneiro Cunha e TRÓPIA. Guilherme. Um olhar para o discurso da Base Nacional Comum Curricular em funcionamento na Área de Ciências da Natureza. Horizontes, v. 36 , n. 1 , p. $144-157$, jan./abr. 2018.

HERNÁNDEZ SAPIERI, Roberto; FERNANDEZ COLLADO, Carlos; BATISTA LUCIO, Maria Del Pilar. Metodologia da Pesquisa. 5 ed. Porto Alegre: Penso, 2013.

LONGHINI, Marcos Daniel. O Conhecimento do Conteúdo Científico e a Formação do Professor das Séries Iniciais do Ensino Fundamental. Revista Investigações em Ensino de Ciências, v. 13. n. 2, p. 241-253, 2008.

MARIANI, Vanessa de Cassia Pistóia. SEPEL. Lenira Nunes. Análise de um Programa de Formação Continuada com Ênfase na BNCC: avaliação e participação docente. Revista Temas em Educação, João Pessoa, Brasil, v. 28, n. 3, p. 24-44, set./dez., 2019a.

MARIANI, Vanessa de Cassia Pistóia. SEPEL. Lenira Nunes. Entendimentos e participação docente no processo de elaboração e tramitação da BNCC. Res., Soc. Dev; 8(12):e318121738 ISSN 2525-3409 I DOI: http://dx.doi.org/10.33448/rsd-v8i12.1738, 2019 b.

MENEGOLLA, Maximiliano e SANT'ANNA, Ilza Martins. Por que planejar? Como planejar?: currículo, área, aula. 22 ed. Petrópolis, RJ: Vozes, 2014. 
NÓVOA, António. Professores imagens do futuro presente. Lisboa: Educa, 2009.

PADILHA, Paulo Roberto. Planejamento dialógico: como construir o projeto político-pedagógico da escola. 4 Ed. São Paulo: Cortez, 2003.

ROSA, Clessi Werner; (et al.). Ensino de física nas séries iniciais: concepções da prática docente. Investigações em Ensino de Ciências, v.12, n. 3, p. 357-368, 2007.

SACRISTÁN, J. G.; PÉREZ-GÓMEZ, A. I. Compreender e Transformar o Ensino. Tradução Ernani F. Da Fonseca Rosa. 4 ed. Porto Alegre: Artmed. 1998. 400p.

SACRISTÁN, J. G. (org.). Saberes e Incertezas sobre o Currículo. Tradução Alexandre Salvaterra. Porto Alegre: Penso, 2013. 542p.

SACRISTÁN, J. Gimeno. Consciência e acção sobre a prática como libertação profissional dos professores. In: NÓVOA, António. Profissão professor. Porto: Porto Editora, 1995.

SACRISTÁN, J.G. O currículo. 3 ed. Porto Alegre: ArtMed, 2000.

VASCONCELlOS, Celso dos Santos. Planejamento: Projeto de Ensino-Aprendizagem e Projeto Político Pedagógico- elementos metodológicos para elaboração d realização, 24 ed. São Paulo: Libertad Editora, 2014.

YIN, Robert K. Estudo de caso: planejamento e métodos. Trad. Daniel Grassi. 3 ed. Porto Alegre: Bookman, 2005.

Yin, Robert K. Pesquisa qualitativa do início ao fim [recurso eletrônico] / Robert K. Yin; tradução: Daniel Bueno; revisão técnica: Dirceu da Silva. Porto Alegre: Penso, 2016. 